\title{
ARTIGOS \\ Indução de resistência a doenças foliares em tomateiro por indutores biótico (Bacillus subtilis) e Abiótico (Acibenzolar-S-Metil)
}

\author{
Fabio Fernando de Araujo $^{1} \&$ Danilo Menezes ${ }^{1}$
}

Faculdade de Ciências Agrárias, Universidade do Oeste Paulista, Rodovia Raposo Tavares, Km 572, Bairro Limoeiro, 19067-175, Presidente Prudente, São Paulo, Brasil.

Autor para correspondência. Fabio Fernando de Araujo (fabio@unoeste.br)

Data de chegada: 24/11/2006. Aceito para publicação em: 15/06/2009

\section{RESUMO}

Araujo, F.F. \& Menezes, D.. Indução de resistência a doenças foliares em tomateiro por indutores biótico (Bacillus subtilis) e Abiótico (Acibenzolar-S-Metil). Summa Phytopathologica, v.35, n.3, p.169-172, 2009

O objetivo deste trabalho foi investigar se doenças foliares do tomateiro (Lycopersicon esculentum) podem ser afetadas pela indução de resistência proporcionada pela aplicação de Bacillus subtilis, no solo e nas folhas e aplicação via foliar de acibenzolar-S-metil. A fim de investigar o modo de ação envolvido no controle foi avaliada a atividade de peroxidases nas folhas do tomateiro tratado com os indutores biótico e abiótico. Para se avaliar a severidade das doenças foliares foi avaliado o número de folhas de tomate com algum sintoma de doença e determinado o percentual de folhas doentes em relação ao total de folhas por planta. $\mathrm{O}$ aumento significativo da concentração de peroxidases nas plantas tratadas com os indutores, assim como a ausência de controle das doenças no tratamento com pulverização direta de B. subtilis nas folhas, são evidências que sugerem que o mecanismo de controle das doenças em questão está relacionado à resistência induzida.

Palavras-chave adicionais: Controle biológico, Lycopersicon esculentum, Rizobacteria.

\section{ABSTRACT}

Araujo, F.F. \& Menezes, D.. Induction of resistance in tomato by biotic (Bacillus subtilis) and abiotic (Acibenzolar-S-Metil) inducers. Summa Phytopathologica, v.35, n.3, p.169-172, 2009

This study was conduced to investigate whether the tomato (Lycopersicon esculentum) leaf diseases may be affected by the induction of resistance provided by the application of Bacillus subtilis, soil and leaf and foliar application of Acibenzolar-S-Methyl. In order to investigate the mode of action involved in the control was measured the peroxidases activity in the leaf of tomato treated with inducers biotic and abiotic. To evaluate the severity of foliar diseases has been estimated the number of leaf of tomatoes with symptoms of disease and determinate the percent of disease leaf in the total of leaf per plant. The significant increase in levels of peroxidase activity in plants exposed to treatment with inducers and lack of control of leaf diseases, in direct spray of $B$. subtilis in the leaves, are evidence that suggest that the mechanism of control diseases in question is related to induction resistance.

Keywords: Biological control, Lycopersicon esculentum, rhizobacteria.

Os diferentes mecanismos de defesa de uma planta (estruturais e bioquímicos) são geneticamente controlados e dependem da expressão dos mesmos no momento e magnitude adequados após o contato do patógeno com o hospedeiro (13). A possibilidade de ativação desses genes, em determinadas condições, torna as plantas mais resistentes aos patógenos, criando-se então o fenômeno da indução de resistência em plantas. Kuc (11) citou que a ocorrência da resistência pode ser de caráter específico atingindo determinadas espécies ou raças de patógenos ou de caráter não específico quando atinge várias doenças ao mesmo tempo sendo chamado de resistência sistêmica. $\mathrm{O}$ aumento do nível de resistência usando agentes externos, sem a modificação do genoma da planta, é conhecido como resistência induzida ou adquirida. A expressão da resistência induzida pode ser local ou ainda, sistêmica quando ela é expressa em locais não expostos diretamente ao agente indutor (21). $\mathrm{O}$ agente indutor pode ser um ativador químico, extratos de células de microrganismos ou microrganismos vivos (15).

Pode-se definir como resistência sistêmica induzida (RSI) aquela que acontece quando plantas, após a exposição a agentes bióticos (microrganismos) ou abióticos (fatores químicos) possam serem induzidas à defesa contra o patógeno, enquanto permanecem espacialmente separados do agente indutor $(14,17)$. Como potenciais agentes indutores bióticos, têm sido avaliadas as rizobactérias promotoras do crescimento de plantas (RPCP) que habitam o solo e com freqüência são isoladas da rizosfera de diversas plantas cultivadas (12). Dentre os mecanismos de ação das rizobactérias no solo a competição por nutrientes, antibiose, produção de enzimas extracelulares e indução de resistência são os mais citados para explicar o controle de patógenos de solo, como também de doenças foliares (6). O desenvolvimento mais recente no campo dos indutores abióticos de resistência em plantas está relacionado com a descoberta de um 
análogo funcional do ácido salicílico, o Acibenzolar-S-Metil (ASM). O ácido promove nas células vegetais estímulo a produção de proteínas específicas relacionadas com a patogênese que são capazes de degradar a parede celular dos fungos e bactérias (5).

Os mecanismos de defesa das plantas contra fitopatógenos envolvem alterações metabólicas que estão correlacionadas com mudanças na atividade de enzimas-chaves nos metabolismos primário e secundário. Neste contexto o grupo de peroxidases representam um papel importante na defesa das plantas. Harkin \& Obst (9) demonstraram a presença de peroxidases nas células vegetais lignificadas. Talvez, elas sejam as únicas enzimas que polimerizam os álcoois em lignina. As peroxidases participam também da biossintese do etileno, e na oxidação de ácido indol acético (AIA) e compostos fenólicos (3). A lignina, juntamente com a celulose e outros polissacarídeos que ocorrem na parede celular das plantas superiores, funciona como uma barreira física à penetração fúngica (19). Sobre isto, diversos trabalhos têm mostrado o envolvimento das peroxidases com a lignificação de papilas $(10,11)$. O aumento na atividade de enzimas de defesa induzida por agentes bióticos ou abióticos (ácido salicílico) permanece no tecido vegetal mesmo após o tratamento com o patógeno virulento (4).

Dentre os mecanismos de ação das rizobactérias no solo a competição por nutrientes, antibiose, produção de enzimas extracelulares e indução de resistência são os mais citados para explicar o controle de patógenos de solo, como também de doenças foliares (6).

Neste contexto o objetivo deste trabalho foi de avaliar o efeito de Bacillus subtilis PRBS-1, isolada do solo, como indutor biótico e Acibenzolar-S-Metil como indutor abiótico no aumento da atividade de peroxidase e controle de doenças foliares em tomate.

\section{MATERIAL E MÉTODOS}

O experimento foi desenvolvido na casa de vegetação e laboratório de Fitopatologia da Faculdade de Ciências Agrárias da UNOESTE, Presidente Prudente, SP. Sementes de tomate, híbrido saladinha, foram semeadas em substrato comercial, acondicionado em bandejas de isopor e aos 35 dias transplantadas para solo $(2 \mathrm{~kg})$ acondicionado em sacos plásticos. As plantas foram conduzidas em casa de vegetação durante 60 dias com reposição de umidade do solo até a capacidade de campo.

Bacillus subtilis, estirpe PRBS-1, isolada de solo sob cultivo de soja (2), foi multiplicado, durante sete dias, em $100 \mathrm{~mL}$ de caldo nutriente $(3 \mathrm{~g}$ de extrato de levedura, $5 \mathrm{~g}$ de peptona e $1000 \mathrm{~mL}$ de água destilada). Decorrido este período o meio de cultura foi centrifugado e o precipitado contendo as células de B. subtilis foi misturado com 100 $\mathrm{g}$ de bentonita. $\mathrm{O}$ material foi homogeneizado e secado por 48 horas em estufa $\left(50^{\circ} \mathrm{C}\right)$ com ventilação forçada durante 24 horas. O produto final teve a concentração de $B$. subtilis avaliada pelo método de diluição em placas, com meio ágar nutriente, apresentando a concentração de $1,0 \times 10^{9}$ células $\mathrm{g}^{-1}$.

Para avaliação do efeito indutor no produto biológico, contendo $B$. subtilis, adicionou-se $200 \mathrm{mg}$ do produto contendo B. subtilis em volta do caule da planta (raio de $2 \mathrm{~cm}$ ) visando a colonização da rizosfera do tomate. Para avaliação do efeito protetor no produto biológico, efetivou-se pulverização foliar semanal de forma preventiva, na dosagem de $1 \mathrm{~g} \mathrm{~L}^{-1}$, utilizando-se pulverizador manual. Foram conduzidos dois tratamentos com pulverização semanal de indutor abiótico Acibenzolar-S-Metil (produto comercial BION 500 WG) na dosagem de $0,05 \mathrm{~g} \mathrm{~L}^{-1}$ e fungicida químico azoxystrobin (Produto comercial AMISTAR $500 \mathrm{WG}$ ) na dosagem de $0,4 \mathrm{~g} \mathrm{~L}^{-1}$. No controle foi utilizado água na pulverização. Foram efetivadas cinco pulverizações semanais durante a condução do experimento.

Para avaliação da atividade da peroxidase amostras de $100 \mathrm{mg}$ da parte aérea das plantas foram macerados em nitrogênio líquido e homogeneizadas em $3 \mathrm{~mL}$ de tampão fosfato de sódio $\left(\mathrm{Na}_{2} \mathrm{HPO}_{4} /\right.$ $\mathrm{NaH}_{2} \mathrm{PO}_{4}$ ) $0,01 \mathrm{~mol} \mathrm{~L}^{-1}, \mathrm{pH} 6,0$ e centrifugadas a $20.000 \mathrm{~g}$, por $25 \mathrm{~min}$ a $4^{\circ} \mathrm{C}$. A atividade da peroxidase de acordo com Araujo et al. (1) foi medida pela adição de $100 \mu \mathrm{L}$ de sobrenadante em $2,9 \mathrm{~mL}$ de tampão fosfato contendo guaiacol e peróxido de hidrogênio. A leitura de absorbância foi feita em espectrofotômetro a $470 \mathrm{~nm}$, durante 10 minutos e a atividade enzimática foi expressa em unidade de enzima (U.E.). Uma unidade de enzima foi definida como a quantidade de extrato enzimático que acusou um aumento na absorbância de 0,001 unidade por minuto. A avaliação enzimática foi realizada aos 50 dias de condução do experimento, uma semana após a última pulverização dos produtos.

Aos 60 dias de condução do experimento as plantas foram avaliadas quanto a danos provocados por doenças foliares causadas por fungos fitopatogênicos. Esta foi obtida a partir da quantificação da porcentagem de folhas com algum sintoma necrótico causados por fungos fitopatogênicos, agentes causais de doenças foliares em tomate (Phytophthora infestans, Septoria lycopersici, Alternaria solani e Stemphylium solani). Os fitopatógenos avaliados ocorreram de forma natural sem inoculação prévia dos mesmos na cultura.

Para avaliação do crescimento das plantas foi medida a altura das plantas em dois períodos (30 e 60 dias). As plantas foram coletadas aos 60 dias sendo separadas as raízes da parte áerea para secagem em estufa com aeração forçada $\left(65^{\circ} \mathrm{C}\right)$ até atingir massa constante. Sendo então determinada a massa seca da parte aérea e raiz

O delineamento experimental empregado foi de blocos casualizados com quatro repetições. Para análise dos dados utilizou-se o teste de comparação múltipla de Tukey $(\mathrm{P}<0,05)$.

\section{RESULTADOS E DISCUSSÃO}

A avaliação do crescimento das plantas demonstra que não ocorreram alterações significativas no desenvolvimento das plantas em todos os tratamentos (Tabela 1 e 2). Foi relatado que Bacillus subtilis, PRBS-1, produz hormônios vegetais que estimularam o desenvolvimento de soja (2). Observou-se, neste trabalho com tomate, que esta mesma estirpe bacteriana não proporcionou, aos 60 dias de condução das plantas, estímulo ao crescimento do tomate.

As plantas inoculadas com Bacillus subtilis, no solo, apresentaram concentrações maiores de peroxidase em seus tecidos quando comparada com o controle ou plantas pulverizadas com B. subtilis na parte aérea (Figura 1). O indutor abiótico acibenzolar-S-metil e o fungicida azoxystrobin também proporcionaram aumentos na atividade da enzima no tecido foliar. A proteção contra os patógenos foliares em tomate, devido a inoculação prévia do B. subtilis, no solo, tem a característica de sistemicidade (Figura 2). Esta característica também foi proporcionada por Bacillus cereus, isolada de filoplano, contra fitopatógenos de tomate (8).

O desempenho, quanto ao controle de doenças foliares no tomate, no tratamento com o indutor abiótico (acibenzolar-S-metil) não foi significativo em relação a testemunha (Figura 2). Este resultado demonstra que a aplicação deste indutor, sozinho, não foi eficiente no 
Tabela 1 Avaliação de altura de plantas (cm), aos 30 e 60 dias, em tomate submetido a tratamento com indutores biótico, abiótico e fungicida em casa de vegetação.

\begin{tabular}{llc}
\hline & \multicolumn{2}{c}{ Altura das plantas } \\
Tratamentos & $\mathbf{3 0}$ dias & $\mathbf{6 0}$ dias \\
\hline Controle & $30,5 \mathrm{a}^{1}$ & $43,3 \mathrm{a}$ \\
B. subtilis (Solo) & $30,1 \mathrm{a}$ & $45,5 \mathrm{a}$ \\
B. subtilis (P. aérea) & $23,3 \mathrm{a}$ & $38,8 \mathrm{a}$ \\
Acibenzolar-S-Metil & $27,5 \mathrm{a}$ & $42,3 \mathrm{a}$ \\
Azoxystrobin & $32,0 \mathrm{a}$ & $50,0 \mathrm{a}$ \\
\hline
\end{tabular}

${ }^{1}$ Médias seguidas da mesma letra, na coluna, não diferem significativamente pelo Teste de Tukey a $5 \%$ de probabilidade

Tabela 2. Avaliação de massa seca da raiz e parte aérea em tomate submetido a tratamento com indutores biótico, abiótico e fungicidas em casa de vegetação.

\begin{tabular}{llc}
\hline & \multicolumn{2}{c}{ Massa seca $\left(\mathbf{g ~ p l}^{-1}\right)$} \\
Tratamentos & $2,00 \mathrm{a}$ & $0,68 \mathrm{a}$ \\
\hline Controle & $2,38 \mathrm{a}$ & $0,87 \mathrm{a}$ \\
B. subtilis (Solo) & $1,82 \mathrm{a}$ & $0,62 \mathrm{a}$ \\
B. subtilis (P. aérea) & $1,78 \mathrm{a}$ & $0,61 \mathrm{a}$ \\
Acibenzolar-S-Metil & $2,30 \mathrm{a}$ & $0,73 \mathrm{a}$ \\
Azoxystrobin &
\end{tabular}

${ }^{1}$ Médias seguidas da mesma letra, na coluna, não diferem significativamente pelo Teste de Tukey a $5 \%$ de probabilidade

controle das doenças foliares do tomate. Tofoli \& Domingues (18) citaram que a redução da severidade em folíolos de tomate bem como o aumento de produção foi observada apenas em programas de aplicação onde o uso de acibenzolar-S-metil foi alternado com difeconazole e azoxystrobin

O controle de doenças, proporcionado pelo B. subtilis, aplicado no solo, foi semelhante ao encontrado pela aplicação do fungicida químico nas folhas. Este efeito apresentou-se como não específico semelhante ao encontrado por Schonbeck et al. (16) que encontrou efetividade da proteção sistêmica, de filtrado de B. subtilis, contra oídio, míldio e outras ferrugens em diferentes hospedeiros.

O controle biológico relacionado a indução de resistência já foi comprovado com rizobactérias $(20,21)$. Também já foi verificada indução de resistência em tomate proporcionado por bactérias residentes no filoplano (8). Araujo et al. (2) selecionaram o isolado PRBS-1 de B. subtilis como um promissor produtor de antibiótico,

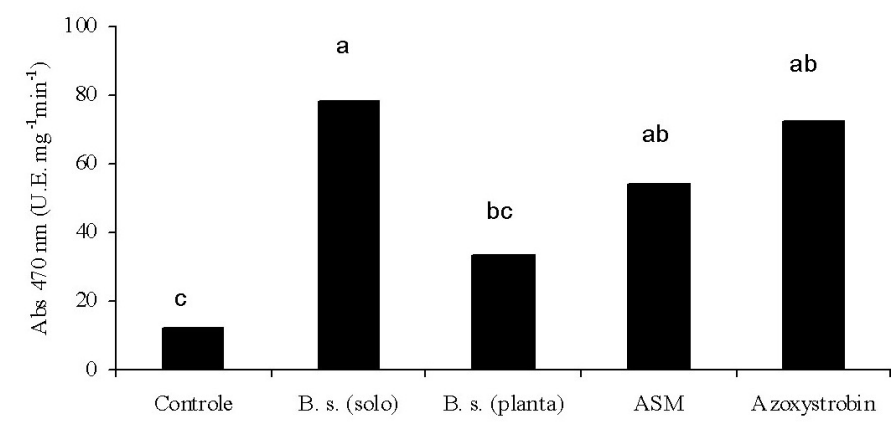

Figura 1. Atividade da peroxidase em folhas de tomateiro tratadas com água (controle), Bacillus subtilis (B. s.) no solo e na parte aérea (planta), Acibenzolar S metil (ASM) e Azoxystrobin. Média seguida da mesma letra não diferem estatisticamente pelo teste de Tukey $(0,05)$. contra fitopatógenos de soja. No tocante ao antagonismo a fitopatógenos o isolado mostrou-se ineficiente no controle de doenças foliares de tomate quando pulverizado preventivamente nas folhas (Figura 2). Este fato, aliado ao aumento da peroxidase nas folhas e resistência não específica, sugere que o controle das doenças foliares proporcionados pela inoculação do isolado na rizosfera pode ter sido fundamentado na resistência induzida.

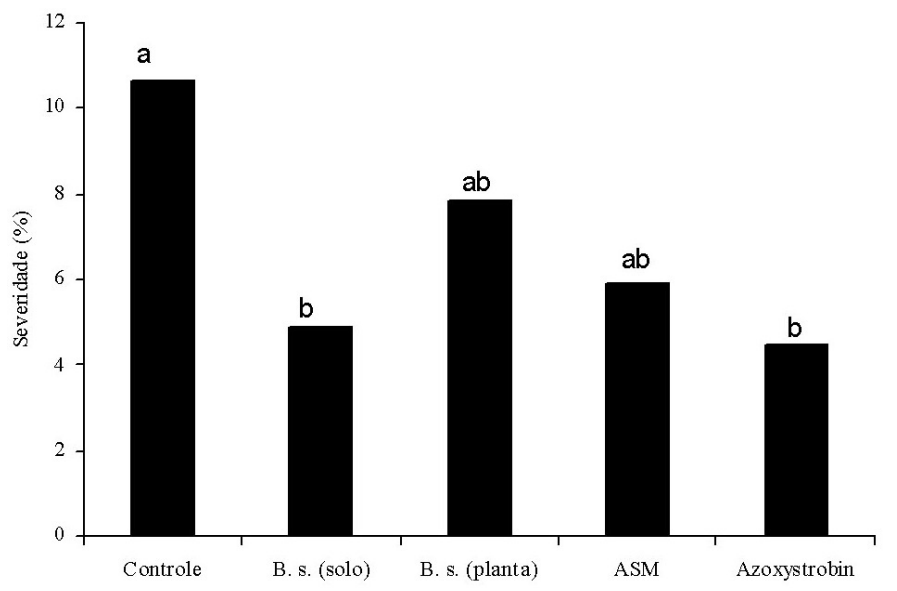

Figura 2. Severidade de doenças expressa em número médios de folhas com sintomas de doenças em plantas de tomate tratadas com: água (controle), Bacillus subtilis (B. s.) no solo e na parte aérea(planta), Acibenzolar S metil (ASM) e Azoxystrobin. Média seguida da mesma letra não diferem estatisticamente baseado em teste de Tukey $(0,05)$.

De acordo com Van Loon et al. (21) na situação de resistência sistêmica induzida (RSI), proporcionada por rizobactéria, supõe-se que o microrganismo produza um sinal translocável que induz proteção em tecidos distantes da raiz onde o antagonista foi introduzido. Sobre as diferenças básicas entre resistência sistêmica induzida e adquirida (RSA) e as dificuldades para comprovação destes eventos foi proposto recentemente que o termo "resistência induzida" seja utilizado para designar todos os tipos de respostas eliciadas que levam a proteção contra doenças, incluindo resposta locais e sistêmicas (7).

Independente da correta classificação da resistência sistêmica proporcionado por Bacillus subtilis, PRBS-1, em tomate, pode-se afirmar que o isolado apresenta grande potencial para uso comercial como rizobactéria promotora de crescimento de planta. A comprovação do efeito indutor contra patógenos foliares de tomate neste isolado aumenta o elenco de efeitos benéficos descrito para este isolado de B. subtilis o que credencia o mesmo para avaliações em condições de campo.

\section{REFERÊNCIAS BIBLIOGRAFICAS}

1. Araujo, A.S.F.; Monteiro, R. T. R.; Cardoso, P. F. Composto de lodo têxtil em plântulas de soja e trigo. Pesquisa Agropecuaria Brasileira, Brasília, v. 40, p. 549-554. 2005a.

2. Araujo, F.F.; Henning, A.A.; Hungria, M. Phytohormones and antibiotics produced by Bacillus subtilis and their effects on seed pathogenic fungi and on soybean root development. World Journal of Microbiology \& Biotechnology, Dordrecht, v.21, p. 1639-1645, 2005b.

3. Cavalcanti, L.S.; Brunelli, K. R.; Stargarlin, J.R. Aspectos bioquímicos e moleculares da resistência induzida. In: Cavalcanti, L. S.; Di Piero, R. M.; Cia, P.; Pascholati S. F.; Resende, M. L. V.; 
Romeiro, R.S. Indução de resistência em plantas a patógenos e insetos. Piracicaba: FEALQ, 2005. 263p.

4. Campos, A. D. Ferreira, A. G.; Hampe, M. M. V.; Antunes, I.F.; Brancão, N.; Silveira, E. P.; Osorio, V. A.; Augustin, E. Atividade de peroxidase e polifenoloxidase na resistência do feijão a antracnose. Pesquisa Agropecuária Brasileira, Brasília, v. 39, p. 637-643. 2004.

5. Col, D. L. The efficacy of Acibenzolar-S-Methyl, na inducer of systemic acquired resistance, against bacterial and fungal diseases of tobacco. Crop Protection, Oxford, v.18, p.267-273, 1999.

6. Enebak, S.A.; Carey, W.A. Evidence for induced systemic protection to fusiform rust in loblolly pine by plant growth-promoting rhizobacteria. Plant Disease, St. Paul, v. 84, p.306-308, 2000

7. Hammerschmidt, H.; Métraux, J. P.; Van Loon, L.C. Inducing resistance: a summary of papers presented at the First International Symposium on Induced Resistance to plant Disease, Corfu, 2000. European Journal of Plant Pathology, Dordrecht, v. 107, p. 1-6, 2001.

8. Halfeld-Vieira B. A.; Vieira Jr. J.R.; Romeiro, R. S.; Silva, H.S.A.; Baract-Pereira, M.C. Induction of systemic resitance in tomato by autochthonus phylloplane residente Bacillus cereus. Pesquisa Agropecuária Brasileira, Brasília, v. 41, p.1247-1252, 2006

9. Harkin, J.M., Obst, J.R. Lignification in trees. Indication of exclusive peroxidases participation. Science, Washington, v.180, p.296-298, 1973

10. Kerby, K.; Somerville, S.C. Purification of an infection-related, extracellular peroxidase from barley. Plant Physiology, Minneapolis, v. 100, p.397-402,1992.

11. Kuc, J. Induced systemic resitance in plants to diseases caused by fungi and bacteria. In: Bailey, J. A.; Deveral, B. J. (Ed.).The dynamics of host defense. Sydney: Academic Press, 1983. p. 191-221.
12. Mariano, R.L.R.; Kloepper, J.W. Método alternativo de biocontrole: resistência sistêmica induzida por rizobactérias. Revisão Anual de Patologia de Plantas, Passo Fundo, v. 8, p. 121-137, 2000.

13. Pascholati, S.F.; Leite, B. Hospedeiro: Mecanismos de resistência. In: Bergamin Filho, A.; Kimati, H.; Amorim, L. Manual de fitopatologia. São Paulo: Ceres, 1995. v. 1, p. 417-453.

14. Pieterse, C. M. J.; Van Loon, L. C. Salicylic acid-independent plant defense pathways. Trends in plant science, London, v. 4, p. $52-58,1999$

15. Romeiro, R. S. PGPR e indução de resistência sistêmica em plantas a patógenos. umma Phytopathologica, Jaguariúna, v. 26, p.177-184, 2000.

16. Shonbeck, F.; Dehne, H. W.; Beight, W. Activation of inespecific resistance mechanism in plants. Journal of Plant Disease and Protection, Stuttgart, v.87, p.654-666, 1980.

17. Stadinik, M. J. Indução de resistência a oídios. Summa Phytopathologica, Jaguariúna, v. 26, p.175-177, 2000.

18. Tofoli, J.G.; Domingues, R.J. Controle da pinta preta do tomateiro com o uso de acibenzolar-S-metil isolado, em mistura com fungicidas e em programa de aplicação. Arquivos do Instituto Biológico, São Paulo, v. 72, p. 481-487, 2005.

19. Vance, C.P.; Kirk, T.K.; Sherwood, R. Lignification as a mechanism of disease resistance. Annual Review of Phytopathology, Palo Alto, v. 18, p. 259-288, 1980.

20. Wei, G.; Kloepper, J. W.; Tuzun, S. Induction of systemic resistance of cucumber to Colletotrichum orbiculare by seven strains of plant growth-promoting rhizobacteria. Phytopathology, St. Paul, v. 81, p. 1508-1512, 1991.

21. Van Loon, L.C.; Bakker, P.A.H.M.; Pieterse, C.M.J. Systemic resistance induced by rhizosphere bacteria. Annual Review of Phytopathology, Palo Alto, v. 36, p.453-483, 1998. 